\title{
Qual será \\ - legado da Copa do Mundo \\ de Futebol de 2014 para o Brasil?
}




\section{RESUMO}

Este artigo procura analisar o legado a deixar pela Copa do Mundo 2014 após o encerramento deste evento. Numa primeira parte, faz-se uma análise do legado de outros grandes eventos, tomando como referência os Jogos Olímpicos de Barcelona 1992 e de Atenas 2004. Numa segunda parte, o artigo centra-se na análise de documentos que ajudem a perceber as actividades e projectos que foram planeados para a Copa. Finalmente, numa terceira parte, procuramos avaliar de que forma os documentos tornados públicos ajudam a perceber qual o legado planeado para a Copa, e quais as áreas em que ele está previsto. Este último aspecto é analisado tendo como referência o legado deixado pelos Jogos Olímpicos de Londres 2012.

Palavras-chave: futebol, legado desportivo, gestão desportiva, políticas desportivas.

\section{ABSTRACT}

This paper seeks to analyze the legacy to be left by the World Cup 2014 after its closure. In the first part, we analyse the legacy of other major events, taking the Barcelona 1992 and Athens 2004 Olympic Games as references. In the second part, the article focuses on the analysis of documents that enable us to understand what activities and projects have been planned for the World Cup. Finally, in the last part we seek to assess how the documents that have been made public help to understand what the planned legacy of the World Cup is and its intended scope. This last aspect is analysed by taking the legacy of the London 2012 Olympic Games as a reference.

Keywords: football, sporting legacy, sport management, sport policies. 


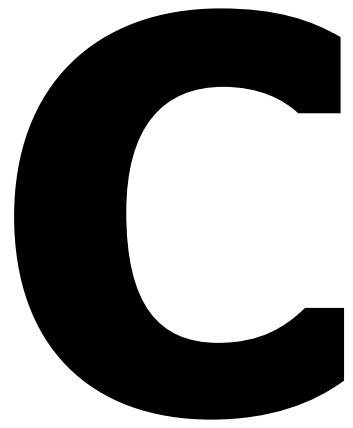

ONSIDERAÇÕES INICIAIS

Rejubilei com a atribuição a Portugal da organização do Campeonato da Europa de Futebol em 2004. Vibrei com os sucessos das candidaturas do Brasil à organização da Copa do Mundo de Futebol de 2014 e do Rio de Janeiro à organização dos Jogos Olímpicos de 2016. Emocionei-me mesmo com as lágrimas do presidente Lula em Copenhaga, em 2009, durante as palavras que proferiu após a atribuição da organização dos J.O. ao Rio de Janeiro. Mas lembro-me também de ter criticado publicamente a construção de tantos estádios em Portugal, um país com recursos escassos e com outras prioridades. Julgo, por isso, perceber a reacção de largos sectores do povo brasileiro e as manifestações que têm decorrido em muitas cidades do Brasil manifestando o seu descontentamento com os gastos de dinheiro público na organização da Copa do Mundo de Futebol.

Devo, porém, ser ponderado. A um ano de distância da Copa e num olhar a partir do exterior, não é fácil falar sobre o tema. Como fazê-lo quando não acompanhei de perto todas as vicissitudes que condicionaram a organização desse grande evento? Antes, durante a preparação da candidatura, e mais tarde, no planeamento e execução das actividades incluídas

Como o Acordo Ortográfico da Língua Portuguesa não elimina todas as diferenças ortográficas observadas nos países que têm o idioma português como oficial, foi mantida a grafia original do texto. no caderno de encargos que justificou a atribuição da Copa do Mundo ao Brasil.

Escolhi, por isso mesmo, não me centrar em demasia sobre as controvérsias actuais nas breves reflexões que agora faço. Antes, procurarei elaborar sobre a forma como poderão ser aproveitados, em benefício do povo brasileiro e do país, os efeitos da organização da Copa e, por acréscimo, dos Jogos Olímpicos do Rio de Janeiro.

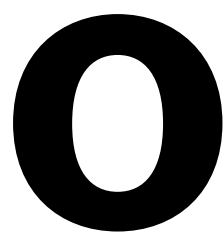

LEGADO DOS GRANDES EVENTOS O mundo tem os olhos no Brasil. Acompanhando, por um lado, a forma como o país tem vindo a responder aos enormes desafios que decorrem da organização desses dois grandes eventos desportivos. E procurando, por outro lado, avaliar de que forma o Brasil aproveitará essa oportunidade para deixar ao país e ao mundo, independentemente dos resultados na competição desportiva, um legado duradouro após a realização desses dois eventos.

Os grandes eventos desportivos mundiais estão, com efeito, a ser aproveitados pelos países organizadores como instrumentos de mobilização de suas melhores capacidades e de suas populações para a realização de grandes projectos que promovam o desenvolvimento desses países. E, a um mesmo tempo, constituam oportunidades privilegiadas de projecção externa.
ANTÓNIO TEIXEIRA MARQUES é professor catedrático da Faculdade de Desporto da Universidade do Porto (Portugal). 
Os Jogos Olímpicos de Barcelona 1992 são o exemplo mais conhecido de como uma cidade e o seu então alcaide, Pasqual Maragall, aproveitaram a sua oportunidade, promovendo o desenvolvimento desportivo, transformando a paisagem de Barcelona e tornando a cidade um dos destinos mais populares na Europa. O modelo dos Jogos de Barcelona é, ainda hoje, estudado por organizadores de grandes eventos desportivos de todo o mundo, sendo o primeiro que foi pensado, desde o seu início, tendo como conceito a transformação da cidade. Houve, é claro, muito dinheiro disponibilizado pelas autoridades e por entidades privadas espanholas. Mas, no caso de Barcelona, apenas $10 \%$ do orçamento foi afectado à construção de novos equipamentos desportivos, sendo o restante utilizado na melhoria da rede de transportes, na habitação, na regeneração da frente marítima da cidade (Beard, 2011) e em outras iniciativas que beneficiaram os cidadãos e se constituíram no orgulho de Barcelona, transformando-a numa cidade aberta ao mundo. E houve ainda arte e engenho para assegurar o sucesso dos jogos no plano desportivo: investindo fortemente, também com o apoio da iniciativa privada, na preparação dos seus atletas, o que levou à obtenção dos melhores resultados desportivos de sempre para o país; criando condições de apoio ao desenvolvimento do desporto de alto nível, com fortes investimentos por todo o país em centros de treino de desportos que antes não se beneficiavam de apoios e que vieram a transformar a Espanha numa potência do desporto, com atletas de altíssimo nível em vários desportos (Taylor, 2012); mobilizando as populações, em particular as mais jovens, para a prática desportiva e incutindo, dessa forma, o gosto pela prática do desporto às gerações mais jovens.

No extremo oposto poderemos referir o exemplo dos Jogos Olímpicos de Atenas 2004. Com custos muito elevados, incluindo os encargos adicionais com o reforço da segurança após o 11 de Setembro de 2001, elevadas dívidas por pagar e inúmeros "elefantes brancos" (21 dos 22 recintos desportivos construídos para os Jogos terão ficado abandonados) (Usborn, 2008), o legado de Atenas tem vindo a ser considerado um dos piores dos Jogos Olímpicos. Para além do sucesso dos eventos desportivos e da criação de algumas infraestruturas para a cidade (como uma nova rede de metrô), Atenas é, a vários títulos, um exemplo do que não deve ser feito no acolhimento dos Jogos.
Muitos outros países e cidades que organizaram eventos semelhantes passaram por situações idênticas. Uns resolveram-nas melhor, outros pagam ainda hoje caro os erros cometidos.

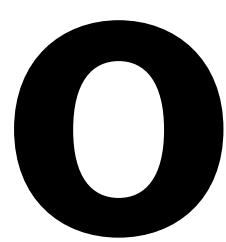

QUEFOI PLANEADO PARAACOPA? O planeamento dos eventos revela-se crucial para assegurar o legado a deixar após o encerramento dos mesmos. Em particular, no que se refere aos equipamentos desportivos, é fundamental definir o aproveitamento futuro dessas infraestruturas, que têm encargos elevadíssimos, não só durante a sua construção, mas também na sua gestão futura.

Nalguns casos, os legados de cidades e países que acolheram grandes eventos estão bem documentados e, nos outros, o próprio processo de preparação das candidaturas para acolher os eventos pode ajudar a perceber quais os efeitos de curto e longo prazo que resultaram, ou resultarão, desses eventos para os países e cidades envolvidos na sua preparação.

Que legado foi pensado para a Copa de 2014, em particular para as grandes estruturas e projectos que foram ou estão a ser executados, após o encerramento da prova? Que políticas foram definidas e que planos foram desenvolvidos para a utilização das infraestruturas desportivas após o final da Copa? Como está a ser utilizado o dinheiro investido na preparação da Copa, e de que forma irão se beneficiar desse investimento o desporto e o povo brasileiro? De que forma os organizadores da Copa aproveitaram a experiência de outros países que tiveram a responsabilidade de organizar os eventos anteriores, procurando aprender com essas experiências e deixando eles próprios novos contributos aos organizadores que se seguirão?

Essas são questões pertinentes que o comité organizador e as autoridades brasileiras não terão deixado de considerar quando assumiram a organização da Copa. Mas é também sabido que entre o planeado e o executado vai sempre alguma diferença, que se traduz de forma mais notória nos projectos concretizados, na observância dos prazos e no controlo da despesa.

Cerimônia de encerramento
dos Jogos Olímpicos
de Barcelona 1992

Cerimônia de encerramento de Barcelona 1992 


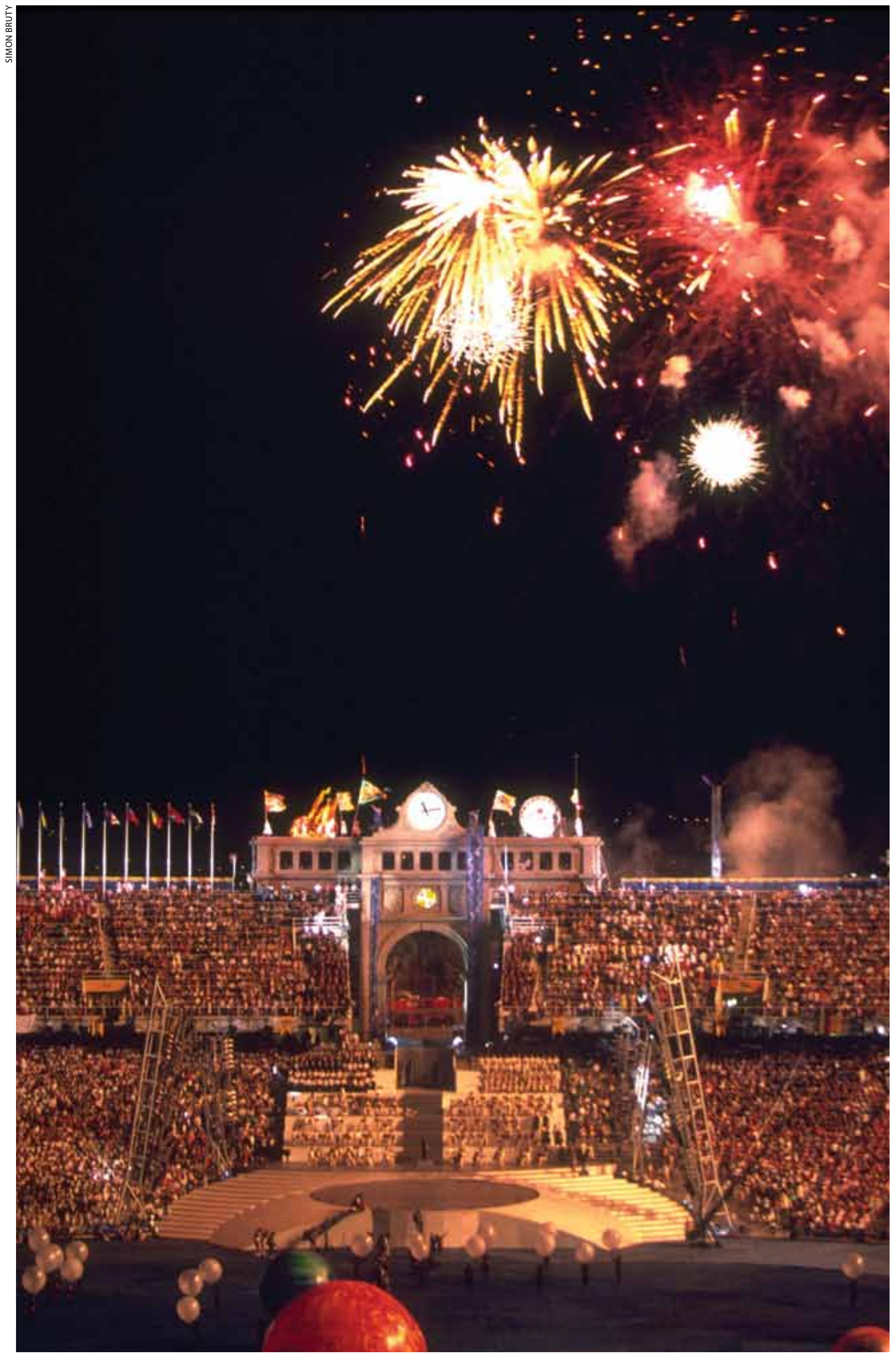


A candidatura do Brasil à organização da Copa do Mundo de 2014 foi ratificada em 2007, tendo a escolha das cidades que iriam sedear o evento sido concluída em 2009 (Wikipédia, s/d).

Temos, portanto, um horizonte temporal que, sendo aparentemente longo, se torna curto, dada a amplitude e a complexidade das operações a executar.

Os planos do comité organizador preveem iniciativas nos domínios dos aeroportos e dos portos, da mobilidade urbana, das comunicações, da cultura, da saúde, da segurança, da sustentabilidade, da transparência e do turismo (ME, 2012). Alguns desses projectos são apresentados com mais detalhe, sendo outros mencionados de uma forma mais genérica.

No âmbito do planeamento de infraestruturas, 0 " 4 " Balanço das Ações do Governo Brasileiro para a Copa 2014", o último tornado público em dezembro de 2012, referia os seguintes projectos e acções (ME, 2012):

- infraestruturas desportivas: 12 estádios, dos quais 6 com conclusão terminada a tempo da realização da Copa das Confederações e 6 a concluir até seis meses antes da Copa do Mundo;

- projectos de mobilidade urbana: 53 projectos, dos quais 45 estão em curso e os restantes terão sido já iniciados em 2013. Esses projectos incluem o desenvolvimento de 2 veículos leves sobre trilhos, 15 BRTs (bus rapid transit), 26 corredores e vias, 10 empreendimentos de estações, terminais, centros de controlo de tráfego, entre outros;

- renovação de aeroportos: 21 novos terminais de passageiros, 7 pistas e pátios de aeronaves, 2 torres de controlo. Desses, 8 empreendimentos foram já concluídos e, relativamente aos restantes, os documentos do governo referem o início das operações pelos concessionários em 3 aeroportos em dezembro de 2012. Esse investimento visa a aumentar a capacidade da rede aeroportuária, uma vez que muitos aeroportos estão já, segundo o ministro do Turismo, a operar acima das suas capacidades (WCB 2014, 2010), e ao conforto das centenas de milhares de turistas esperados para a Copa; - portos: 5 terminais de passageiros, 1 alinhamento de cais e 1 píer, com o objectivo de melhoria da infraestrutura turística, dos quais 5 portos estão em obras, prevendo-se a sua conclusão em 2013;

- outras: o ministro dos Transportes do Brasil anunciou também, em 2008, a construção de um comboio de alta velocidade ligando Campinas, São Paulo e
Rio de Janeiro. No entanto, em 2010 foi anunciado que essa linha não será inaugurada antes do final de 2016 (Wikipédia, s/d).

Para infraestruturas de "suporte e serviços" temos:

- telecomunicações: 12 projectos para a expansão de redes de fibra óptica, com $70 \%$ da rede já concluída, e 32 projectos de implantação de equipamentos e sistemas, dos quais 22 foram iniciados, estão em licitação, ou em preparação para licitação;

- turismo: 400 intervenções nas cidades-sede e entorno, com conclusão até dezembro de 2013;

- qualificação profissional: oferta de 240 mil vagas em programas de qualificação profissional em 117 municípios, com 119 mil pré-matriculados e 54 mil matriculados;

- hotelaria: expansão em $15 \%$ da oferta hoteleira nas cidades-sede e entorno até 2014;

- segurança pública: criação de 14 centros integrados de Comando e Controlo (2 nacionais e 12 regionais), dos quais 12 já iniciados, e desenvolvimento de acções para defesa do evento (em curso).

No planeamento (ME, 2012) estavam ainda incluídas iniciativas nas áreas da:

- energia: reforço dos sistemas de fornecimento de energia;

- comunicação: definição de estratégias de: 1) reforço e projecção externa da imagem do Brasil "como país competitivo e inovador, com grande potencial de negócios e capacidade de realização, que se desenvolve de maneira sustentável e com inclusão social" e "como país hospitaleiro, criativo, alegre, unido, trabalhador, aguerrido, que valoriza a diversidade, e rico em belezas naturais"; e 2) divulgação do legado da Copa - "da valorização da Marca Brasil ao investimento no capital intelectual e humano e às obras de infraestrutura, abrindo espaço para a comunicação dos Jogos Olímpicos e Paralímpicos Rio 2016". Esses projectos estão a ser desenvolvidos através da comunicação digital e das redes sociais (em curso), da definição do conceito institucional e da linha criativa, de campanhas como "O Brasil inteiro jogando junto" (em curso), "Copa de 2014. O turismo brasileiro já entrou em campo", e de campanhas de promoção internacional a se realizar em vários países (em curso); 
- cultura: o planeamento inclui ainda "iniciativas culturais" de divulgação e promoção no mundo da cultura brasileira, em particular da gastronomia, dos museus das cidades-sede da Copa, ou da riqueza e diversidade do património histórico, arquitectónico e do artesanato.

Finalmente, o planeamento prevê ainda (ME, 2012) medidas nas áreas da saúde, da sustentabilidade, da transparência (foi elaborado um plano para combater a fraude e a corrupção nos projectos de construção das novas infraestruturas - Plano "Jogando Limpo"), do ambiente e preservação da biodiversidade (a mascote "Tatu-bola" pretende sensibilizar o Brasil e o mundo para a preservação de uma espécie vulnerável) (Costa et al., 2013), embora menos explicitadas em projectos e iniciativas concretas.

As previsões de investimento em empreendimentos de infraestruturação e serviços somam, segundo o governo brasileiro (" $4{ }^{\circ}$ Balanço das Ações do Governo Brasileiro para a Copa 2014”), mais de R $\$ 26$ bilhões, dos quais $\mathrm{R} \$ 7,1$ bilhões, isto é, cerca de $27,3 \%$, a investir na construção de estádios (ME, 2012).

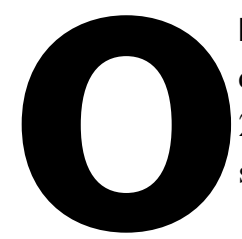

LEGADO DA COPA Qual o legado que a Copa do Mundo de Futebol de 2014 deixará ao Brasil após as quatro semanas de realização do evento?

Dizia Luís Fernandes, representante do governo federal no Comitê Organizador Local, que "O evento será um sucesso e esse é o grande legado" (Costa et al., 2013).

Não será pouco, certamente, garantir como legado o sucesso de um grande evento desportivo. Mas constituirá o sucesso desportivo da Copa retorno suficiente de um tão grande investimento financeiro para um país com desafios tão grandes pela frente e ainda tantas carências noutras áreas?

Acreditamos que o legado da Copa não se limitará ao sucesso da competição desportiva. Como, aliás, outros documentos oficiais referem. O próprio governo brasileiro (ME, 2012) fala da valorização da Marca Brasil, do investimento em capital humano e da infraestrutura que ficará após a Copa.

Se o conceito de Barcelona se centrou na ideia "Os jogos da regeneração da cidade" (Beard, 2011), qual é o conceito por trás do planeamento da Copa? Nos documentos que consultamos não nos lembramos de ter visto alusão a esse assunto.
Qual a utilidade no futuro dos equipamentos desportivos construídos, para os quais foi canalizada uma parte importante dos investimentos financeiros? De que forma os outros investimentos feitos foram devidamente controlados nos seus gastos e se traduzem efectivamente em mais-valias para a população e para o país e não apenas em proveitos para alguns? São algumas das questões que, a esse propósito, podem ser colocadas, mas às quais será, porventura, ainda prematuro dar uma resposta. E no entanto já existe algum mal-estar, que tem origem nas questões que identificamos atrás.

Para além dos aspectos mais óbvios relacionados com o atraso na edificação das infraestruturas e com o descontentamento das populações, devido ao aumento exponencial dos gastos num país com carências graves, designadamente nas áreas da educação e da saúde, alguns sectores da sociedade brasileira assinalam as dificuldades em gerir o projecto em toda a sua complexidade (Leite, $\mathrm{s} / \mathrm{d}$ ). Questiona-se, assim, o dinheiro investido na Copa, quando faltam recursos para melhorar a escola pública ou o sistema de saúde pública. Como alguém questionou recentemente num contexto similar (Vivar et al., 2013): "Não é mais mobilizador e indutor do orgulho de uma Nação ter bons hospitais, boas escolas, gente educada e culta, do que gastar o dinheiro em grandes eventos desportivos?". Os quais se transformam, não poucas vezes, "em tábua de salvação de interesses privados e políticos questionáveis, em negócios de todo o tipo e corrupção".

Nos documentos do governo brasileiro a que tivemos acesso (ME, 2012) o legado a deixar pela Copa era assinalado de forma explícita em seis áreas:

1) mobilidade urbana, com desenvolvimento de novos veículos, corredores rápidos para transportes públicos, novas estações, terminais e centros de controlo de tráfego, estruturas que contribuirão para a melhoria da mobilidade e da qualidade de vida das populações;

2) renovação de aeroportos, visando a aumentar a capacidade da rede aeroportuária já a operar acima dos seus limites e, dessa forma, servir melhor as populações e os turistas que visitam o Brasil;

3) construção de novas infraestruturas portuárias, com o objetivo de fomentar o turismo num país com muitas potencialidades a este nível, ainda não devidamente exploradas;

4) melhoria de outras infraestruturas nas telecomunicações, na energia, na hotelaria, na segurança pú- 
blica, em apoio da modernização do país e do seu esforço de desenvolvimento;

5) promoção da imagem do Brasil, dentro e fora do país, que será tanto mais bem-sucedida quando aos êxitos no plano desportivo se possam somar outros relacionados com a melhoria do bem-estar das populações e o desenvolvimento do país;

6) "last but not the least", modernização da infraestrutura desportiva, com a construção dos novos estádios a proporcionar melhores condições para a prática de futebol de alto nível e para a organização de espectáculos desportivos. No debate público sobre a relevância desse último aspecto surgem dúvidas sobre a utilidade futura de alguns desses estádios, em particular em regiões do Brasil nas quais o nível dos espectáculos desportivos não terá no futuro, isto é, uma vez terminada a Copa, uma relevância compatível com o investimento feito. E onde, como consequência, os gastos de gestão tornarão essas estruturas insustentáveis, levando à sua rápida degradação.

Isso dito, podem parecer ainda curtos esses resultados face a um tão grande investimento. $\mathrm{O}$ que poderia ter sido, ainda, feito para potenciar esse legado?

A análise da experiência, recente, de organização dos Jogos Olímpicos de Londres 2012 traz-nos contributos importantes a esse respeito (IOC, 2012).

A primeira lição de Londres é que o legado deixado após os Jogos foi objecto de um plano director elaborado com detalhe em vários níveis e em todas as áreas. De entre essas referir-me-ei, apenas, àquelas que me parecem não constar dos planos dos organizadores da Copa e poderiam constituir um importante legado.

- O legado desportivo - o Plano de Londres (IOC, 2012) deixa claro a atenção que os organizadores conferiram à promoção de um maior acesso de jovens e pessoas de todas as idades aos equipamentos desportivos e à prática do desporto, através de: 1) desenvolvimento de novas estratégias, políticas governamentais e alterações legislativas; 2 ) criação de novos clubes desportivos na comunidade; 3) criação de novos projectos comunitários de desporto em todo o país; 4) organização de jogos escolares e festivais desportivos a nível regional; 5) formação de professores primários para apoiar e promover a prática desportiva entre os jovens. Na área do legado desportivo é pertinente, também, referir os cuidados postos na recolha, sistematização e organização de informação

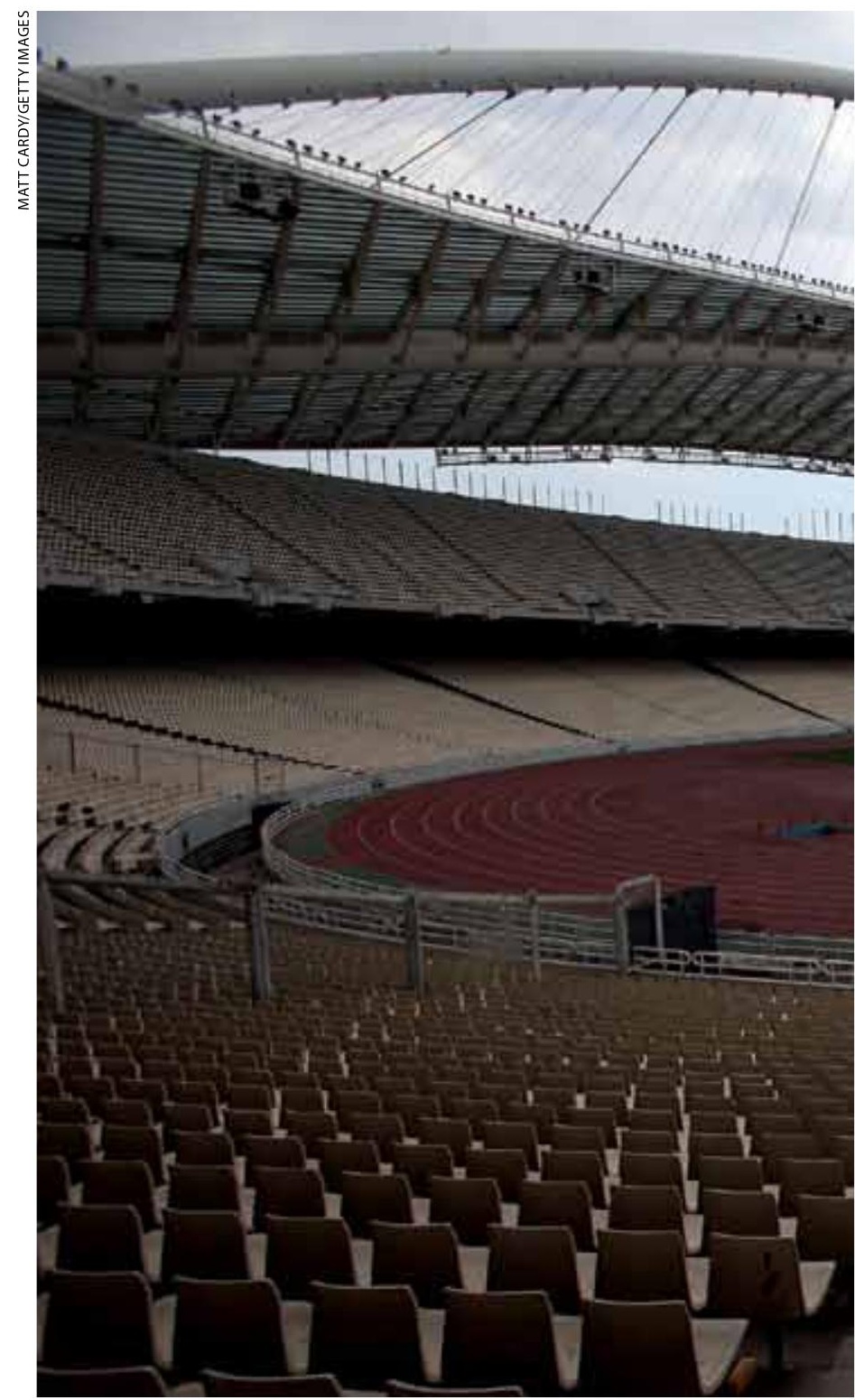

que permitirá futuramente a transferência de know- how entre países e o acompanhamento e partilha de experiências na organização de grandes eventos.

- O legado na regeneração urbana de zonas degradadas da cidade, com a construção de novos equipamentos desportivos, residências, escolas e centros de saúde.

- O legado ambiental, favorecendo e/ou estabelecendo novos padrões para a construção e o desenvolvimento sustentável, a utilização e preservação da energia, a reciclagem dos resíduos e da água, tornando as cidades mais verdes, encorajando a biodiversidade, criando um forte compromisso com o respeito e a protecção do ambiente. Recorde-se que os organizadores dos J. O. de Inverno de 1994 em Lillehammer, 
do o reconhecimento do desporto e da actividade física como instrumentos promotores da saúde.

- O legado intangível, a que se referem também os documentos dos organizadores da Copa 2014, embora com um alcance mais limitado do que aqui se propõe. Ou seja, o que fica após o evento, embora seja mais difícil de ver e de medir: 1) o estímulo de atitudes, do orgulho nacional, da atenção e respeito do mundo pela capacidade de um país e dos seus cidadãos, das suas empresas e organizações para acolher e organizar com sucesso grandes eventos; 2) a inspiração das jovens gerações através das realizações desportivas dos atletas e dos valores do desporto; o respeito pelos deficientes e pelas diferenças culturais e religiosas, pela igualdade.
São realizações dessa natureza que unem os países e os seus cidadãos em torno dos seus grandes projectos. Projectos dessa envergadura, que mobilizam as populações e reforçam a coesão dos povos, são um grande legado e uma lição que se deve manter no futuro. Mesmo se as coisas parecem não correr tão bem, como está a acontecer no Brasil.

As fortes movimentações populares iniciadas em junho de 2013 nas principais cidades brasileiras, reivindicando melhor educação e melhor saúde, estão a relançar o debate sobre um evento que parece não ser tão consensual, agora, entre a população brasileira, e não deixarão de influenciar o legado da Copa e, também, seguramente, dos Jogos Olímpicos do Rio de Janeiro.

\section{BIBLIOGRAFIA}

BEARD, M. "Lessons of Barcelona: 1992 Games Provided Model for London... and Few Warnings", in Evening Standard, March 21, 2011. Disponível em: http://www.standard.co.uk/news/lessons-ofbarcelona-1992-games-provided-model-for-london-and-few-warnings-6382929.html.

COSTA, F.; BALTAR, M.; IANNACCA, M. "Secretário Exalta Copa no Brasil: 'Não Somos Menores do que Ninguém'", in Globoesporte.com, 30/janeiro/2013. Disponível em: http://globoesporte. globo.com/futebol/copa-do-mundo/noticia/2013/01/secretario-exalta-copa-no-brasil-naosomos-menores-do-que-ninguem.html.

IOC - International Olympic Committee. Factsheet. London 2012 Facts \& Figures. Update November 2012. November, 2012. Disponível em: http://www.olympic.org/Documents/ Reference_documents_Factsheets/London_2012_Facts_and_Figures-eng.pdf.

LEITE, J.S. "Copa do Mundo 2014: Oportunidade Desperdiçada?", in ADG Brasil, s/d. Disponível em: http://adg.org.br/blog/blog/copa-do-mundo-2014-oportunidade-desperdicada.

ME - Ministério do Esporte. "4을alanço das Ações do Governo Brasileiro para a Copa 2014". Ministério do Esporte, Governo Federal do Brasil, dezembro de 2012. Disponível em: http:// www.copa2014.gov.br/sites/default/files/publicas/12272012_balanco_copa_geral.pdf.

TAYLOR, A. "How the Olympic Games Changed Barcelona Forever", in Business Insider, July 26, 2012. Disponível em: http://www.globalpost.com/dispatch/news/regions/europe/spain/120726/ olympic-games-barcelona-legacy-olympic-curse.

USBORN, S. "After The Party: What Happens when the Olympics Leave Town", in The Independent, August 19, 2008. Disponível em: http://www.independent.co.uk/sport/olympics/after-theparty-what-happens-when-the-olympics-leave-town-901629.html.

VIVAR, R. F.; FUERTES, J. V. J.; MONREAL, L. H. "La Derrota de un Proyecto llusionante", in EI País, Opinión, Setembro 11, 2013. Disponível em: http://elpais.com/elpais/2013/09/10/ opinion/1378835879_996852.html.

WCB - World Cup Brazil 2014. "Law Reduces Bureaucracy of Airports Buildings. Ask as Fraud Investigator". June 8, 2010. Disponível em: http://www.v-brazil.com/world-cup/2014/lawbureaucracy-airport-building-easier.

WIKIPÉDIA. "Copa do Mundo Fifa de 2014", in Wikipédia, s/d. Disponível em: http://pt.wikipedia. org/wiki/Copa_do_Mundo_FIFA_de_2014. 